31. Curray, J. R. The Quaternary of the United States. H. E. Wright and D. G. Fred, eds. Princeton Univ. Press, Princeton, NJ (1965).

32. Bloom, A. L. The Late Cenozoic Glacial Ages. K. K. Turekian, ed. Yale Univ. Press, New Haven, CT (1971).

33. Goudie, A. Environmental Change. Oxford Univ. Press, 244 pp. (1977).

34. Kerr, R. A. “An Early Glacial Two-Step?”'Sci. 221: 143-144 (1983).

35. Broecker, W. S., M. Ewing, and B. C. Heezen. "Evidence for an Abrupt Change in a Climate Close to 11,000 Years Ago', Amer. J. Sci. 258: $429-448$ (1960).

36. Ruddiman, W. F. and A. McIntyre. "Time-Transgressive Deglacial Retreat of Polar Waters from the North Atlantic'. Quaternary Res. 3: 117-130 (1973).

37. Fairbridge, R. W. "Dating the Latest Movements of the Quaternary Sea-Level". Transactions, New York Academy of Sciences 20: 471-482 (1958).

38. Morner, N. A. "The Plum Point Interstitial: Age, Climate, and Subdivision', Canadian J. Of Earth Sci. 8: 1423-1431 (1971).

39. Brooks, C. E. P. Climate Through the Ages. Ernest Benn, London (1949).

40. Livingston, D. A. "Speculations on the Climatic History of Mankind". In Climates Past and Present, B. J. Skinner, ed. Wm. Kaufmann, Inc., Los Altos, CA, pp. 80-85 (1979).
41. Write, H. E. "Climate Change in the Eastern Mediterranean Region: The Natural Environment of Early Food Production in the Mountains North of Mesopotamia". Final Report, Univ. of Minnesota, Contract NOMR-710 (33), Task No. 380-129.

42. Weiner, J. S. Man's Natural History. Weidenfeld and Nicolson, London, 254 pp. (1971).

43. Guthrie, R. D. "The Evidence for Middle-Wisconsin Peopling of Beringia: An Evaluation". Quaternary Res. 22: 231-241 (1984).

44. Campbell, K. E. and D. Frailey. "Holocene Flooding and Species Diversity in Southwestern Amazonia'. Quaternary Res. 21: 369-375 (1984).

45. Martin, P. S. "Africe and Pleistocene Overkill”. Nature 212: 339-342 (1966)

46. Martin, P. S. "Prehistory Overkill'. In Pleistocene Extinctions. R. S. Martin and H. E. Write, eds. Yale Univ. Press, New Haven CT, pp. 75-120 (1967).

47. Krantz, G. S. "Human Activities and Megafaunal Extinctions”. Ameri. Sci. 58: 164-170 (1970).

48. Tringham, R. Hunters, Fishers and Farmers of Eastern Europe. Hutchinson Univ. Libr. London, 240 pp. (1971).

49. Marx, R. F. “Why Cádiz Must be Saved”. Sea Frontiers 32 (3): 198-203 (1986).

\title{
DIGITAL ELECTRONICS WHERE WE ARE AND WHERE WE ARE GOING
}

\author{
Lt. Col. Daniel H. Weiss \\ Tactical and Advanced Avionics Program Manager \\ Headquarters United States Air Force \\ Directorate of Maintenance and Supply
}

\section{ABSTRACT}

The paper synopsizes the current situation with regard to the nature of the red as well as the blue-grey forces as their capabilities impact future avionics systems. The paper describes today's climate as it relates to the avionics posture of the current and future fighter air forces, congressional desires and budgetary direction. The paper describes the current US Air Force response in the terms of modular systems. The benefits of modular avionics systems are delineated and the impact of software on this new hardware approach are explained. The way to the future is postulated in terms of the threat versus force posturing and the impact on both today's and future weapons systems. The paper concludes with several recommendations which, while they will somewhat alter traditional industrial relationships, will also address the future avionics needs of the US Armed Force.

Based on a paper presented at the 1986 Digital Avionics Systems Conference.

U.S. Government work not protected by U.S. copyright.

\section{INTRODUCTION - NATURE OF THE THREAT}

To understand where we should be going with avionics, or more precisely, digital electronics, it is best to appreciate where we are and what has occurred in that arena. In turn, this will form the basis that will provide an understanding and appreciation for what should be done in the future.

Today, we face two potential groups of adversaries. Those represented by Russia and affiliated Russian (Eastern European [Warsaw] Pact) nations, termed Red nations, and those represented by any other nation that may or may not necessarily be affiliated with the United States, termed the Blue-Grey nations.

In looking at these potential adversaries, one can qualify and quantify their postures and relate those postures to recent events. By doing so, one can best understand how the US military, and in particular the US Air Force, must posture itself now to prepare for the potential threat in the future.

The Red forces can best be characterized by their large, in-place armies and air forces. Their operating locations are 
well known as are their traditional battlegrounds. A study of recent history will reveal that, with few exceptions, the same forces have fought in the same places, albeit with different weapons (i.e., the French with Russia in the Napoleonic Wars, and the Germans with Russia in World War II). As then, now, and in the future, the Red forces are in place to protect the Eastern European way of life. The Red forces including the USSR and all its satellites, are extremely well prepared and their combat capability, particularly from an electronic standpoint, is modern.

To counter those forces, we have in place resources that, along with those of our allies, are at least a credible deterrent to the Red forces. Because of the severity of recent (WWII) losses by the Red nations, and the strength and proximity of the forces of the Blue nations (US and US affiliated nations), it is unlikely that the Red forces will attack without extreme provocation. The continued update of the Blue forces and their high degree of readiness, which in large is enabled and supported by an extensive in-place logistic support capability, ensures the status quo of the Red/Blue situation.

The Blue-Grey situation is somewhat more dynamic and has continued to change over the past years. The Blue-Grey nations are represented primarily by those in the Third World. These nations have been supplied arms by either the Red or the Blue nations and in some cases by both. Their allegiance has sometimes changed over the years (i.e., Iran, Libya, Ethiopia), and in some cases has changed more than once from Blue to Red to Blue (i.e., Egypt). This causes the traditional identification of potential allies and adversaries to sometimes be a challenging task.

It is with the Blue-Grey nations that the most recent Blue conflicts have been fought; e.g. For example, Grenada (US), the Falklands (British) and, most recently, Libya. The objectives of Blue-Grey nations in many cases are often somewhat obscure. They do not necessarily defend traditionally valued things such as the integrity of one's territorial limits or trade relationships, but rather ideologies or arbitrary territorial claims (the Gulf of Sidra's Line of Death). The unpredictability of the Blue-Grey nations' threshold of tolerence further complicates the ability of Blue nations to gauge their reaction to a given situation because the Blue-Grey nations judge their ability to deal with larger nations based not upon traditional measures (i.e., size, capability land/or proximity of potential adversarial forces) but rather with their degree of ideological purity. The belief they adhere to is that the higher that purity, the greater the likelihood that the BlueGrey forces will triumph regardless of the quantity, quality and/or proximity of the Blue forces that potentially oppose them.

In addition to the character of the Blue-Grey conflict, one must account for the potential timing of a conflict, the location and the equipage of Blue-Grey forces.

The location of potential Blue-Grey conflicts is worldwide. As recent situations have shown, these conflicts have been and most likely will continue to be of a come-as-you-are nature. The United States will not have in place a logistic support base of any particular significance, and the weapons systems that will be faced may be from any of a great number of origins and may possess any number of unique capabilities. Worse yet, if the Blue-Grey country has been supplied by both Blue and Red nations, we may have to face our own weapons as well as Red weapons. Also, if the weapons have been in place for a considerable period of time, we may face those that have been retired by the providing nation. Their retirement from the front line of either the Blue or Red forces, however, makes them none the less lethal although they can be defeated as was recently seen in Libya.

\section{SITUATION CHANGING STRATEGY}

The current business strategy, strongly influenced by the Competition in Contracting Act (CICA) as it applies to the fielding and support of US military forces, is continuing to evolve. Competition is the keynote of all activities. In addition, warranties are for the most part required as second sourcing and component breakout. It appears that sole source for initial and/or follow-on requirements is no longer an accepted way of addressing Department of Defense needs.

With regard to the impact upon digital systems, three other seemingly unrelated situations also must considered.

First, the Department of Defense has just changed its compensation policy with regard of retirement. This, in addition to the fact that the US military has over the last eight years been continually paid less than its civilian commercial counterparts, will probably result in an evolution in the composition of the armed forces. While the total number of personnel will probably remain the same, fewer are likely to go past their first or second term in service. This will result in a much higher turnover rate and an armed force with less experience. To address this issue, it is believed the systems that personnel maintain, while most likely more complex, will have to be easier to troubleshoot/repair by personnel who have not received today's high level of training or benefited from many years of experience.

\section{BUDGETARY CONSTRAINTS INCREASING}

Secondly, the cost of weapons systems continues to rise and to stay within budgetary constraints their planned life expectancy continues to increase. It is not unreasonable to expect systems such as the F-15 and F-16 to be in the active inventory in 2010 - 35 years after being first fielded! To remain viable, current weapons systems will have to be candidates for the same capabilities being planned for the more advanced weapons systems that will be fielded in the ' 90 s and incorporated in such platforms as the Advanced Tactical Fighter (ATF).

Thirdly, in general the reliability of avionic components has continued to increase over the years while the half-life of avionics has continued to decrease. With the Defense Department being a very small customer in relation to the commercial customer, an interesting situation has developed. At a given point in time with the military buying systems maintaining commonality to the piece part level because of logistics concerns and with new avionics systems/system components being introduced every three to five years, the likelihood that a particular part is readily available on the commercial market to satisfy point in time military need is 
extremely unlikely. If the part is available, the cost is high because usually only one or two firms still make it. More often than not, it is this situation that puts the military back into a sole source position where Congress desires it not to be.

Although appearing to be an impossible situation, a solution must be sought. In seeking the solution, concepts developed with perhaps different objectives in mind may be reexamined and assessed for potential application and reorientation.

\section{MODULAR AVIONICS PROVIDING KEY}

The recent trend toward modular avionics systems, which started as a trickle appears to have the potential to become a torrent. The recent selection of two companies to field the future integrated electric war force system (INEWS) that employ the PAVE PILLAR modular avionics system approach, the core systems [the VHSIC modular (VM)-1750 digital signal processor and the common signal processor (CSP).], the ATF bound integrated communication navigation identification avionics (ICNIA) system as well as the integrated inertial reference assembly (IIRA), and the ultra reliable radar (URR), which may, too, be ATF bound, sends an important signal about modular systems. Not to be ignored because, if for no other reason than the size of the market, are the possible mid-life updates of the RF-4, F-15 and F-16 fleets. It is anticipated that these updates will employ modular systems to ensure the mature weapons systems that use them are as electronically capable as the new weapons systems that employ the same approach.

Add to all this the congressional desire for commonality, at least at the system level, of weapons systems and, of late, at least the stabilization if not the decline of military funding levels, and you realize that something other than business as usual must occur with regard to the planning and procurement or future avionics systems.

It would appear that a different response to the traditional approach to standardization is in the offing. With the introduction of ICNIA, INEWS, URR, CSP, and IIRA comes a concentration at the interface level as opposed to the traditional standardization concern at the piece part level and/or at the subsystem level (i.e. inertial navigation system, radio transceiver, etc.). This traditional approach to standardization not only brings a great number of positive features and opportunities, but also new areas of concern.

\section{ADOPTING NEW APPROACH}

Common interfaces will allow the new systems to adopt a resource sharing approach, assuming that on line testing with coverage and confidence levels that are at least in the three Sigma range is integral to the architecture of the modular systems. Because the interface is the primary focus, anything at all in terms of avionics may be put on the other side of the interface without concerning one's self with the specific piece part capability or level of technology. In addition to the focus on interface standards, an avionics integrity program (AVIP) also is being advocated. If put into place as now conceived, AVIP would support a preemptive removal rather than a remove-upon-failure approach.

It is believed that this approach policy rather can lead to a smaller and less highly skilled work force that concentrates its attention on the replacement of components instead or the analysis of failure modes and effects. Given the functional commonality at the interface, the technician would not have to be continually trained just because the technology of the systems being supported has changed. Also, given that an AVIP is in being, the capabilities of a depot could then be concentrated on the analysis of failure modes and mechanisms instead of just repair activities. As new technologies are identified to meet a particular interface, it will then be only the depots, not the depots plus the field activities, that will have to adapt to the technological approach. Because of a more stable work force, this adaptation process at depot level is seen as a much easier, less time consuming and, most importantly, less expensive task than training those in the depot as well as those in field units.

\section{EXPANDING COMPLEXITY}

While there are many benefits to be gained by integrating to a standard interface, there are some potentially detrimental situations as well. With the increasing complexity of systems and the desire for ever increasing levels of integration as well as graceful degradation, which can only be supported by resource sharing, problems can occur. Moving more data faster increases the potential for software crashes. With larger and larger software schemes designed to deal with the ever increasing range and complexity of both the Red and Blue-Grey threat, the total lines of code increase on almost a geometric basis. As the nature of the Red/Blue-Grey threat intensifies, so must the Blue forces' ability to respond rapidly to any and all threats.

The way to the future, while far from easy, seems to be relatively defined and possible. The emphasis appears to be on a modular approach that will support an AVIP. While this is the hardware emphasis, the nature of the software emphasis should not be ignored, but rather addressed in conjunction with the hardware. Reusable, traceable code appears to be the software answer. The objective should be how to link together, in a unique manner, system capabilities or portions of software capabilities that are known to be able to address and defeat a threat. While some new capabilities may have to be developed, they should be both in the minority and of attainable size, which should support their relatively rapid and successful fielding. The implication to use Ada is more then just coincidental. It is purposeful and planned that Ada will offer the opportunity to address and perhaps render manageable the software problems we are experiencing today.

\section{RETROFIT GAINING IMPORTANCE}

Plans should continue to field new aircraft but this planning should be done with retrofit in mind. This combined forward fit plus retrofit approach will benefit many communities. With many aircraft having the same capabilities (from a hardware perspective) and the standardization con- 
centration at the interface versus the component level, systems planned for further advanced aircraft can be installed on today's in service aircraft. This will decrease the risk to future aircraft while affording today's aircraft the same capabilities as those that future aircraft will require/possess. As mentioned above, the envisioned RF-4, F-15 and F-16 mid-life updates offer such an opportunity.

A new logistic support approach is planned to be introduced in light of the evolving threat. The envisioned new approach addresses the desire to reduce total numbers of personnel and level of both skill and experience in field units. To balance this reduction, the depots will gain an analytical capability they do not now possess and a resource management capability afforded by AVIP that, in view of the ever increasing cost and importance of avionics, is very much needed. The composition and capabilities of the future logistic support force in terms of personnel and their particular skills will continue to change while the half life of electronics will continue to decrease.

\section{REPOSTURING LOGISTIC SUPPORT}

In summary, the threat is becoming ever more dynamic, while the Red threat is certainly significant, it is exacerbated considerably by the Blue-Grey threat. In reacting to these threats, we must be much more responsive. The response must, in addition to reflecting the reaction to the threat, be done with respect to congressional desires for competition, commonality and second sourcing. The reposturing of the logistic support force must enable it to support more complex systems with personnel who have not had the benefit of many years of training or experience on many weapons systems. The new support force should be required to accomplish the replacement of system components on a preemptived basis while leaving the analysis of actual and potential failures to depot level-based activities.

A significant emphasis must be placed on retrofit as an accepted and preplanned force multiplication/vitalization strategy. All efforts to include retrofit, forward fit, and new weapons systems procurement should concentrate on viable interfaces that are accepted as government/industry standards such as the MIL STD 1553B digital data bus and the $1750 \mathrm{~A}$ instruction set architecture. The new designs, by definition, should support a competitive strategy because all potential vendors will understand the interface they must meet. These new modular systems that will be competitively procured should be both supported and complemented by a viable warranty structure.

The initial introduction of several, and certainly varied, industrial teaming arrangements, dictated by the needs of the Department of Defense and satisfied by the unique capabilities of the team members, should continue at perhaps a more ambitious rate. It is believed that by addressing all of the above actions combined with the realities of the present and expanding capabilities of our potential adversaries, as well as the future posture of US forces, a more capable and more easily supported fighting and winning force will evolve.

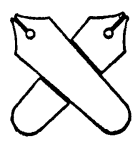

\author{
FACULTY OF SCIENCE AND TECHNOLOGY \\ KEIO UNIVERSITY \\ 14-1, HIYOSHI, 3CHOME, KOHOKUKU, YOKOHAMA \\ 223 JAPAN
}

\begin{abstract}
The 1987 Symposium on Information Theory and Its Applications, Nov. 19-21, Enoshima Island, Japan. (International sessions in English are included). Information: Prof. Shinsaku Mori, Symposium Chairman, Dept. of Elec. Eng. Keio Univ., 3-14-1, Hiyoshi, Kohoku-ku, Yokohama 223 Japan. Tel. +8114-63-1141, ext.3318. Fax. +81-44-63-3421.
\end{abstract}

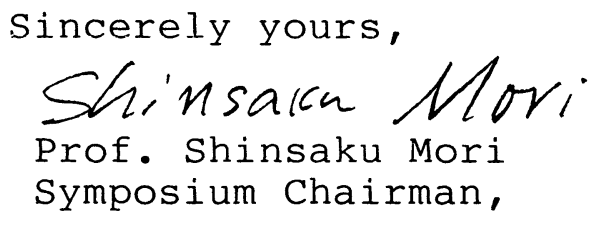

